\title{
Differences in Health Information Literacy Competencies among Older Adults, Elderly and Younger Citizens
}

\author{
Isto Huvila, Noora Hirvonen, Heidi Enwald, and Rose-Mharie Åhlfeldt \\ Department of ALM, Uppsala University, Uppsala, Sweden and Information \\ Studies, Åbo Akademi University, Åbo, Finland \\ isto.huvila@abm.uu.se \\ Information Studies, Åbo Akademi University, Åbo, Finland and Information \\ Studies, University of Oulu, Finland \\ \{firstname.lastname\} @oulu.fi \\ University of Skövde, Skövde, Sweden \\ rose-mharie.ahlfeldt@his.se
}

\begin{abstract}
To address the research gap on age-based differences in health information literacy (HIL), we investigate how younger (born 1960-) and older adults (1946-1960), and elderly citizens (-1945) differ from each other by their HIL competencies. Data were collected with an online survey of patients using the Swedish national electronic health record system. Altogether 2587 users responded. One-way ANOVA with post hoc tests revealed several differences between the groups: younger adults were less likely to value health information than older adults; older adults and elderly were least likely to compare information from multiple sources and had trouble in determining health information needs; older adults were most likely to have trouble understanding health terminology and the elderly to have difficulties in understanding medicinal package labels. The study shows that HIL is not necessarily improving or declining but adapting to challenges of advanced age.
\end{abstract}

Keywords: Health information literacy, older adults, elderly, young.

\section{Introduction}

In spite of the growing corpus of research on older citizens and their health information literacy (e.g. [1-5]), there are still relatively few studies that would have investigated how older people deviate from other age groups in their competencies to find, evaluate, and use health information [6]. To address this research gap, this study examines agebased differences in health information literacy competencies with a focus on older adults. An adequate understanding of the health information literacy of older citizens is crucial for providing health information for this group in a manner that would encourage and help them to become better informed in health-related matters. 
Post-print of Huvila, I.; Hirvonen, N.; Enwald, H. \& Åhlfeldt, R.-M. Differences in Health

Information Literacy Competencies Among Older Adults, Elderly and Younger Citizens. In

Kurbanoğlu, S.; Špiranec, S.; Ünal, Y.; Boustany, J.; Huotari, M. L.; Grassian, E.; Mizrachi, D. \&

Roy, L. (Eds.) Information Literacy in Everyday Life. ECIL 2018. Communications in Computer

and Information Science, Springer, 2019, 136-143.

\subsection{The Concept and Measurement of Health Information Literacy}

The concept of health information literacy refers to information literacy competencies in health settings or the combination of the concepts of information literacy and health literacy [7]. The Medical Library Association based its health information literacy definition on the American Library Association's [8] definition of information literacy. According to it, health information literacy refers to "the set of abilities needed to: recognize a health information need; identify likely information sources and use them to retrieve relevant information; assess the quality of the information and its applicability to a specific situation; and analyze, understand, and use the information to make good health decisions." [7, p. 294]. The definition is not far removed from recent health literacy definitions [9-10] and most of them present obtaining information central in gaining an adequate health literacy level [11]. However, the concept of health information literacy places emphasis on information discovery and the active role of individuals in seeking health information from various sources [11-12] and draws from research on information behavior and practices.

While in health literacy research so-called objective measures are typically used to evaluate health literacy levels, empirical studies on health information literacy have focused on people's self-evaluated competencies. Niemelä et al. [13] as well as Eriksson-Backa et al. have developed screening tools with which these competencies can be evaluated. Both measures include statements which are meant to describe key elements of health information literacy: the ability to identify health information needs, to find information, evaluate its credibility, and to use this information in decisionmaking.

Niemelä et al. [13] suggested, based on a pilot study among upper secondary school students and a factor analysis, that their tool, consisting of ten statements, could be divided into three separate factors, namely, motivation, confidence, and evaluation. Besides these three factors, the perceived ability to understand health related terminology was considered an essential element of health information literacy and therefore analysed separately. Moreover, a question about a diagnosis of dyslexia was included into the screening tool. The tool by Eriksson-Backa et al. [4] includes eight statements and was first used to examine the health information literacy of elderly Finns aged $65-79$ years.

\subsection{Health Information Literacy and Age}

Previous research on the HIL of specific age groups have focused on young people (e.g., [4, 14-15]) and elderly citizens [1-5, 16-17]. For example, Enwald et al. [5] used a four-item version of the screening tool by Niemelä et al. [13] and examined the HIL of a random population-based sample of older people (65 or more). According to the results, older people were rather motivated to seek health information but faced difficulties in assessing the reliability of information from online sources and understanding health terminology. Many of them also found it difficult to know whom to believe on health issues [5]. In addition, the relationship between everyday health information literacy and attitudes towards mobile technology among older people were investigated. The users of both traditional and mobile information technology differed from non-users in that they were more confident in their abilities in evaluating online 
health information, determining who to believe in health issues, and understanding health related terminology. Also, positive opinions towards mobile information technology were linked to perceiving fewer problems in the areas of everyday health information literacy [5].

Eriksson-Backa et al. 2012 [4] found that among Finnish seniors (65 to 79 years old), HIL was associated with both interest in health information and health information seeking activity. Furthermore, HIL was associated with education and health; those who had higher education and rated their health as good were also likely to be confident in their abilities to find and use information. No differences were observed among age groups and gender was connected only to confidence in the ability to use obtained information in order to take care of one's own health [4]. Older people and issues relating to their health information literacy has also been a subject of a review study by Suri et al. [18].

In turn, Hirvonen et al. [14-15], using the screening tool by Niemelä et al. [13] studied the HIL of young Finnish men and found that they lacked motivation to seek for health information but were confident in their abilities to find and evaluate it. Among young men, HIL was associated with education as well as health promoting behavior and physical fitness [14-15]. Enwald et al. [19] found that when compared to these young men, adults with high risk for metabolic syndrome, with a mean age of 45 years, were more highly motivated to seek health information but lacked confidence to find, understand, and evaluate it. Based on previous research, there are indications of agebased differences in health information literacy but few studies have focused on comparing age groups to each other.

\subsection{Aim and Research Questions}

The aim of this study is to increase understanding of age-based differences in health information literacy. This is examined among people using a patient accessible electronic health record system in Sweden. The research questions are:

Q1. How do people perceive their health information literacy abilities?

Q2. What kind of differences can be identified in these perceptions between different age groups?

\section{Material and Methods}

\subsection{Data Collection}

The data were collected with an anonymous national survey of patients who had consulted their medical records online using the national patient accessible electronic health record system (Journalen) in Sweden. All users logging in to the system were prompted to take the survey between January and June 2016. Altogether 2,587 users responded. Aspects related to health information literacy were measured using 11 items focusing on information literacy, self-perceived competence and capability to obtain and use health information, and to influence one's own health (see Table 2). They were 
Post-print of Huvila, I.; Hirvonen, N.; Enwald, H. \& Åhlfeldt, R.-M. Differences in Health Information Literacy Competencies Among Older Adults, Elderly and Younger Citizens. In Kurbanoğlu, S.; Špiranec, S.; Ünal, Y.; Boustany, J.; Huotari, M. L.; Grassian, E.; Mizrachi, D. \& Roy, L. (Eds.) Information Literacy in Everyday Life. ECIL 2018. Communications in Computer and Information Science, Springer, 2019, 136-143.

based on the measures by Niemelä et al. [13] and Eriksson-Backa et al. [4].

\subsection{Data Analysis}

The questionnaires were categorised into three groups based on the respondents' age: Elderly (born -1945), Older Adults (1946-1960), and Younger Adults (1960-). Groupwise differences in responses were tested using one-way ANOVA in SPSS 24.0 with Tamhane T2 post hoc test. The measures were treated as continuous variables.

\section{Results}

\subsection{Respondent Characteristics}

The respondents were from 18 to 98 year old people with a mean age of $50.65(\mathrm{SD}=52)$. Of the respondents who indicated their gender $(n=2427$ of the total number of respondents 2587), 67\% ( $n=1629)$ were women and 33\% $(n=798)$ were men. The number of respondents who indicated their age $(n=2456)$ in age-based groups can be found in Table 1 .

Table 1. Respondents grouped by age.

\begin{tabular}{lll}
\hline Category & $\mathrm{N}$ & $\%$ \\
\hline Younger Adults & 1415 & 57.6 \\
Older Adults & 707 & 28.8 \\
Elderly & 334 & 13.6 \\
Total & 2456 & 100 \\
\hline
\end{tabular}

\subsection{Health Information Literacy}

Overall, most respondents agreed that it is important to be informed about health issues (Table 2). Some $80 \%$ of the respondents thought they were able to influence their own health, knew were to seek health information, and applied health information to their own lives. Around $70 \%$ of them liked to get and compare health information from a variety of sources, and around $60 \%$ found it easy to determine when health information is needed. 
Post-print of Huvila, I.; Hirvonen, N.; Enwald, H. \& Åhlfeldt, R.-M. Differences in Health Information Literacy Competencies Among Older Adults, Elderly and Younger Citizens. In Kurbanoğlu, S.; Špiranec, S.; Ünal, Y.; Boustany, J.; Huotari, M. L.; Grassian, E.; Mizrachi, D. \& Roy, L. (Eds.) Information Literacy in Everyday Life. ECIL 2018. Communications in Computer and Information Science, Springer, 2019, 136-143.

Table 2. Responses to the health information literacy statements.

\begin{tabular}{|c|c|c|c|c|}
\hline Statement & $\begin{array}{l}\text { Agree } \\
\mathrm{n}(\%)\end{array}$ & $\begin{array}{l}\text { Neutral } \\
\mathrm{n}(\%)\end{array}$ & $\begin{array}{l}\text { Disagree } \\
\mathrm{n}(\%)\end{array}$ & $\mathrm{N}$ \\
\hline $\begin{array}{l}\text { It is important to be informed about } \\
\text { health issues }\end{array}$ & $2231(91.5)$ & $166(6.8)$ & $42(1.7)$ & 2439 \\
\hline $\begin{array}{l}\text { I like to get health information from a } \\
\text { variety of sources }\end{array}$ & 1779 (73.9) & $445(18.5)$ & $183(7.6)$ & 2407 \\
\hline $\begin{array}{l}\text { I compare the health information I have } \\
\text { received from various sources. }\end{array}$ & $1638(68.4)$ & $498(20.8)$ & $260(10.9)$ & 2396 \\
\hline $\begin{array}{l}\text { It is easy to determine in what situations } \\
\text { I need health information }\end{array}$ & $1520(63.4)$ & $654(27.3)$ & $225(9.4)$ & 2399 \\
\hline I know where to seek health information & $1915(79.7)$ & $327(13.6)$ & $160(6.7)$ & 2402 \\
\hline $\begin{array}{l}\text { I apply health related information to my } \\
\text { own life and/or that of people close to } \\
\text { me }\end{array}$ & $1841(78.1)$ & $382(16.2)$ & $135(5.7)$ & 2358 \\
\hline $\begin{array}{l}\text { Health related terminology and } \\
\text { statements are often difficult to } \\
\text { understand }\end{array}$ & $874(36.8)$ & $462(19.5)$ & $1038(43.7)$ & 2374 \\
\hline $\begin{array}{l}\text { It is easy to understand the medicinal } \\
\text { package inserts, labels or prescription. }\end{array}$ & $1794(74.6)$ & $310(12.9)$ & $300(12.5)$ & 2404 \\
\hline $\begin{array}{l}\text { I get way too much information about } \\
\text { health. }\end{array}$ & $206(8.7)$ & $865(36.6)$ & $1293(54.7)$ & 2364 \\
\hline I don't want to think about health issues. & $145(6.2)$ & 450 (19.1) & $1762(74.8)$ & 2357 \\
\hline I can influence my own health. & $1778(78.3)$ & $321(14.1)$ & $172(7.6)$ & 2271 \\
\hline
\end{tabular}

More than one third of the respondents found it difficult to understand health related terminology and some $12 \%$ had trouble in understanding medicinal package inserts, labels, or prescription. Less than one in ten thought they get too much health information and six percent of them did not want to think about health issues.

\subsection{Differences by Age}

Significant group-wise differences were found between the three age groups (see Table 3 ). The Older Adults were more likely than the Younger Adults to agree that it is important to be informed about health issues. However, there was no significant differences between the Elderly and Older Adults, or Younger Adults and Elderly. In turn, Older Adults and the Elderly were least likely to compare information from multiple sources and to think that it is easy to determine when they need health information. In comparison to Younger Adults, Older Adults considered that health related terminology is difficult to understand, and to Elderly that it is more difficult to understand medicinal information. The Older Adults and Elderly did also consider that they get too much health information. 
Post-print of Huvila, I.; Hirvonen, N.; Enwald, H. \& Åhlfeldt, R.-M. Differences in Health Information Literacy Competencies Among Older Adults, Elderly and Younger Citizens. In Kurbanoğlu, S.; Špiranec, S.; Ünal, Y.; Boustany, J.; Huotari, M. L.; Grassian, E.; Mizrachi, D. \& Roy, L. (Eds.) Information Literacy in Everyday Life. ECIL 2018. Communications in Computer and Information Science, Springer, 2019, 136-143.

Table 3. Significant group-wise differences in responses $(n=2198$; Elderly $n=262$; Older Adults n=614; Younger Adults n=1322) to HIL statements.

\begin{tabular}{|c|c|c|c|c|c|}
\hline Statement & I & $\mathrm{J}$ & $\begin{array}{l}\text { Mean } \\
\text { Diff. (I-J) }\end{array}$ & $\begin{array}{l}\text { Std. } \\
\text { Error }\end{array}$ & Sig. \\
\hline $\begin{array}{l}\text { It is important to be informed } \\
\text { about health issues. }\end{array}$ & Older Adults & Younger Adults & .102 & .032 & .004 \\
\hline \multirow{2}{*}{$\begin{array}{l}\text { I compare the health } \\
\text { information I have received } \\
\text { from various sources }\end{array}$} & Elderly & Younger Adults & -.185 & .069 & .023 \\
\hline & Older Adults & Younger Adults & -.196 & .055 & .001 \\
\hline \multirow{2}{*}{$\begin{array}{l}\text { It is easy to determine in what } \\
\text { situations I need health } \\
\text { information }\end{array}$} & Elderly & Younger Adults & -.178 & .064 & .016 \\
\hline & Elderly & Older Adults & -.170 & .069 & .044 \\
\hline $\begin{array}{l}\text { Health related terminology and } \\
\text { statements are often difficult to } \\
\text { understand. }\end{array}$ & Older Adults & Younger Adults & .173 & .063 & .018 \\
\hline $\begin{array}{l}\text { It is easy to understand the } \\
\text { medicinal package inserts, } \\
\text { labels or prescription }\end{array}$ & Elderly & Younger Adults & -.240 & .073 & .003 \\
\hline \multirow{2}{*}{$\begin{array}{l}\text { I get way too much information } \\
\text { about health }\end{array}$} & Elderly & Younger Adults & .195 & .065 & .008 \\
\hline & Older Adults & Younger Adults & .160 & .048 & .003 \\
\hline
\end{tabular}

\section{Discussion and Conclusions}

In this study, we examined age-based differences in health information literacy among users of Journalen, the Swedish national electronic health record system. The results indicate that, when compared to younger adults, older adults are more likely to value the importance of being informed about health issues but also have difficulties in understanding the terminology used. Both older adults and the elderly were less likely than the younger adults to compare information from multiple sources and more likely to think they obtained too much information i.e. experience information overload. In turn, the elderly were likely to have difficulties in understanding medicinal package labels and to determine when they needed health information.

In line with previous studies [4-5, 19], older adults seem to be motivated to find health information but face difficulties in understanding it. Interestingly, older adults were most likely to have difficulties in understanding health related terminology whereas the elderly had trouble in understanding information in medicinal packages and prescriptions. At older age, people often face health concerns and are therefore in need 
for information on health issues. In a study by Enwald et al. [5] elderly citizens faced difficulties in assessing the reliability of information from online sources and understanding health terminology. Therefore, even when the respondents had logged in to an electronic health record system, and thus were possibly more motivated in health issues than the general population, they seem to be facing the same difficulties than elderly citizens in other studies. In this study, it is to be noted however that the overwhelming majority $(91.5 \%)$ of all respondents considered that being informed about health issues is important.

Studies on health literacy indicate that inadequate health literacy is more prevalent in older age [20]. In the light of the findings of this study as well as previous research, age differences could be found as well. However, it seems that the health information literacy skills of the respondents are not necessarily improving-or declining-but changing and adapting to new issues and challenges of advanced age. An awareness of the importance of health issues is increasing in this phase of life. The results give indication of the varying environmental and situational challenges populations face when obtaining and evaluating health information in everyday situations.

When interpreting the results, it should be noted that the respondents of this study do not represent the Swedish population as a whole since they were all users of the Journalen and volunteered to participate. Moreover, women were overrepresented in the sample. The HIL measure was based on self-evaluated abilities which may not indicate actual, measurable, skills but reflect people's views on how their own skills align with the demands they are faced with.

The study contributes to previous research on health information literacy by increasing understanding of age differences among citizens. A better understanding of the health information literacy of older citizens is useful in providing health information to make them better informed in health-related matters. Libraries devoted to teach health information literacy could tailor their education according to the age-related information needs and on how people perceive their health information literacy abilities. In the light of the findings, older citizens appear both as interested in health information and having difficulties in understanding, comparing and coping with larger amounts of it. This would seem to call for specific measures to address this particular group and moreover, to work proactively to prepare older adults with appropriate information literacies to cope with their developing information needs and problems. Also, generally speaking, national electronic health record systems are getting more common and also librarians might come across questions relating to their use. Future studies should attempt to achieve randomised population-based sampling. The users of electronic health records should also be compared to non-users as usage may indicate differences in motivation, health concerns and status, as well as technical skills. 
Post-print of Huvila, I.; Hirvonen, N.; Enwald, H. \& Åhlfeldt, R.-M. Differences in Health Information Literacy Competencies Among Older Adults, Elderly and Younger Citizens. In Kurbanoğlu, S.; Špiranec, S.; Ünal, Y.; Boustany, J.; Huotari, M. L.; Grassian, E.; Mizrachi, D. \& Roy, L. (Eds.) Information Literacy in Everyday Life. ECIL 2018. Communications in Computer and Information Science, Springer, 2019, 136-143.

\section{Acknowledgements}

The data collection was a part of the work of the Swedish DOME research consortium (projectdome.wordpress.com). This study was conducted in collaboration between DOME consortium and the Academy of Finland funded research project Taking Health Information Behaviour into Account (HIBA).

\section{References}

1. Yates, C., Stoodley, I., Partridge, H., Bruce, C., Cooper, H., Day, G., Edwards, S.L.: Exploring Health Information Use by Older Australians within Everyday Life. Library Trends 60(3), 460-478 (2012)

2. Eriksson-Backa, K.: The Role of Online Health Information in the Lives of Finns Aged 65 to 79 Years. International Journal of Networking and Virtual Organisations 4, 13(1), 5-23 (2013)

3. Eriksson-Backa, K., Ek, S.: Health Information Literacy and Communication in Healthcare Contexts: A Study of Older Finnish Adults. In: Proceedings of the 17th International Symposium on Health Information Management Research (ISHIMR 2015), 24-26 June 2015, pp. 77-91. York St. John University and University of Sheffield, York (2015)

4. Eriksson-Backa, K., Ek, S., Niemelä, R., Huotari, M.L. Health Information Literacy in Everyday Life: A Study of Finns Aged 65-79 Years. Health Informatics J. 18(2), 83-94 (2012)

5. Enwald, H., Hirvonen, N., Kangas, M., Keränen, N., Jämsä, T., Huvila, I., Korpelainen, R.: Relationship Between Everyday Health Information Literacy and Attitudes Towards Mobile Technology Among Older People. In: Kurbanoğlu, S., Boustany, J., Špiranec, S., Grassian, E., Mizrachi, D., Roy, L. (eds.) Information Literacy in the Workplace: 5th European Conference, ECIL 2017. Saint-Malo, France, 18-21.9.2017. Revised Selected Papers, pp. 450-459 (Communications in Computer and Information Science Series Vol. 810). Springer International Publishing, Cham, Switzerland (2018) https://link springer.com/content/pdf/10.1007\%2F978-3-319-74334-9 47.pdf

6. Huvila, I., Ek, S., Enwald, H., Eriksson-Backa, K., Hirvonen, N., Känsäkoski, H.: Taking health information behaviour into account in the design of e-health services. Finnish Journal of eHealth and eWelfare 8(4), 153-163 (2016) https://journal.fi/finjehew/article/view/60194

7. Shipman, J.P., Kurtz-Rossi, S., Funk, C.J.: The Health Information Literacy Research Project. Journal of Medical Library Association 97(4), 293-301 (2009)

8. ALA. Presidential Committee on Information Literacy: Final Report (1989) http://www.ala.org/acrl/publications/whitepapers/presidential

9. Sørensen, K., Van den Broucke, S., Fullam, J., Doyle, G., Pelikan, J., Slonska, Z., Brand, H., (HLS-EU) Consortium Health Literacy Project European: Health Literacy and Public Health: A Systematic Review and Integration of Definitions and Models. BMC Public Health 12, 80 (2012)

10. Mårtensson, L., Hensing, G.: Health Literacy - A Heterogeneous Phenomenon: A Literature Review. Scandinavian Journal of Caring Sciences 26 (1), 151-160 (2012)

11.Huhta, A.-M.., Hirvonen, N., Huotari, M.-L.: Concepts Related to Health Literacy in Online Information Environments: A Systematic Review with an Emphasis on Approach to Information. In: Kurbanoğlu, S., Boustany, J. Špiranec, S., Grassian, E., Mizrachi, D., Roy, L. (eds.) Information Literacy in the Workplace: 5th European Conference, ECIL 2017. SaintMalo, France, 18-21.9.2017. Revised Selected Papers, pp. 450-459. (Communications in Computer and Information Science Series Vol. 810) Springer International Publishing, Cham, 
Post-print of Huvila, I.; Hirvonen, N.; Enwald, H. \& Åhlfeldt, R.-M. Differences in Health Information Literacy Competencies Among Older Adults, Elderly and Younger Citizens. In Kurbanoğlu, S.; Špiranec, S.; Ünal, Y.; Boustany, J.; Huotari, M. L.; Grassian, E.; Mizrachi, D. \& Roy, L. (Eds.) Information Literacy in Everyday Life. ECIL 2018. Communications in Computer and Information Science, Springer, 2019, 136-143.

Switzerland (2018)

12. Lawless, J., Toronto C.E., Grammatica, G.L.: Health Literacy and Information Literacy: A Concept Comparison. Reference Services Review 44(2), 144-162 (2016)

13. Niemelä, R., Ek, S., Eriksson-Backa, K., Huotari, M-L.: A Screening Tool for Assessing Everyday Health Information Literacy. Libri 62(2), 125-134 (2012)

14. Hirvonen, N., Ek, S., Niemelä, R., Pyky, R., Ahola, R., Korpelainen, R., Huotari, ML.: Everyday Health Information Literacy in Relation to Health Behavior and Physical Fitness: A Population-Based Study among Young Men. Library and Information Science Research 38(4), 308-318 (2016)

15. Hirvonen, N., Niemelä, R., Ek, S., Korpelainen, R., Huotari, M-L.: Socio-Demographic Characteristics Associated with the Everyday Health Information Literacy of Young Men. Information Research 20(1), paper: isic25 (2015)

16. Eriksson-Backa, K., Enwald, H., Hirvonen, N., Huvila, I.: Health Information Seeking, Beliefs about Abilities, and Health Behaviour among Finnish Seniors. Journal of Librarianship and Information Science (Online First) https://doi.org/10.1177/0961000618769971

17. Enwald, H., Kangas, M., Keränen, N., Immonen, M., Similä, H., Jämsä, T., Korpelainen, R.: Health Information Behaviour, Attitudes towards Health Information and Motivating Factors for Encouraging Physical Activity among Older People: Differences by Sex and Age. Information Research 22(1), paper isic1623 (2017)

18. Suri, V.R., Chang, Y.-K., Majid, S., Foo, S.: Health Information Literacy of Senior Citizens - A Review. In: Kurbanoğlu, S., Špiranec, S., Grassian, E., Mizrachi, D., Catts, R. (eds.) Information Literacy: Lifelong Learning and Digital Citizenship in the 21st Century. Second European Conference, ECIL 2014, Dubrovnik, Croatia, 20.-23.10.2014, Revised Selected Papers, pp.128-137 (Communications in Computer and Information Science Series Vol. 492) Springer International Publishing, Switzerland (2014)

19. Enwald, H., Hirvonen, N., Huotari, ML., Korpelainen, R., Pyky, R., Savolainen, M., Salonurmi, T., Keränen, AM., Jokelainen, T., Niemelä, R.: Everyday Health Information Literacy among Young Men Compared with Adults with High Risk for Metabolic Syndrome - A Cross-Sectional Population-Based Study. Journal of Information Science 42(3), 344-355 (Special Issue of I3 Conference, at Aberdeen, UK, June 2015) (2016)

20. Ratzan, S.C., Parker, R.M.: Health Literacy - Identification and Response. Journal of Health Communication 11(8), 713-715.(2006) 